\title{
Determination of urinary 2,5-hexanedione concentration by an improved analytical method as an index of exposure to $n$-hexane
}

\author{
Isao Saito, Eiji Shibata, Jian Huang, Naomi Hisanaga, Yuichiro Ono, Yasuhiro Takeuchi
}

\begin{abstract}
2,5-Hexanedione is a main metabolite of n-hexane and is considered as the cause of n-hexane polyneuropathy. Therefore, it is useful to measure 2,5-hexanedione for biological monitoring of exposure to $n$-hexane. The analytical methods existing for $n$-hexane metabolites, however, were controversial and not established enough. Hence, a simple and precise method for determination of urinary 2,5-hexanedione has been developed. Five $\mathrm{ml}$ of urine was acidified to $\mathrm{pH} 0.5$ with concentrated hydrochloric acid and heated for $\mathbf{3 0}$ minutes at $90-100^{\circ} \mathrm{C}$. After cooling in water, sodium chloride and dichloromethane containing internal standard were added. The sample was shaken and centrifuged. 2,5-Hexanedione concentration in an aliquot of dichloromethane extract was quantified by gas chromatography using a widebore column (DB-1701). Urinary concentration of 2,5 -hexanedione showed a good correlation with exposure to $n$-hexane ( $n=50, \mathbf{r}=0.973, \mathrm{p}<0.001)$. This method is simple and precise for analysis of urinary 2,5-hexanedione as an index of exposure to $n$ hexane.
\end{abstract}

$\mathrm{n}$-Hexane is a widely used solvent in industry and well known to cause polyneuropathy. ${ }^{1-3}$ It is metabolised to 2,5-hexanedione, 2,5-dimethylfuran, 2 -hexanol, and $\alpha$-valerolactone. 2,5-Hexanedione, which is one of the main metabolites of $n$-hexane, is considered as the ultimate neurotoxic metabolite. ${ }^{4-6}$ Many investigations into the relation between urinary metabolites and exposure to $\mathrm{n}$-hexane have been

Aichi Prefectural Institute of Public Health, Tsujimachi, Kita-ku, Nagoya 462 Japan

Isao Saito

Department of Hygiene, Nagoya University School of Medicine, Showa-ku, Nagoya 466 Japan

E Shibata, J Huang, N Hisanaga, Y Ono, Y Takeuchi carried out and good correlations have been found between exposure to $\mathrm{n}$-hexane and urinary 2,5hexanedione concentration. ${ }^{7-11}$ These results suggest that measurement of urinary 2,5-hexanedione concentration could be used for biological monitoring of exposure to n-hexane. Fedtke and Bolt showed that 4,5-dihydroxy-2-hexanone was a main urinary metabolite of $\mathrm{n}$-hexane but this metabolite was converted to 2,5-hexanedione by acid hydrolysis. ${ }^{12}$ Fifty ppm is proposed as the eight hour time weighted average threshold limit value (TLV-TWA) of $n$-hexane by The American Conference of Governmental Industrial Hygienists (ACGIH) ${ }^{13}$ and $40 \mathrm{ppm}$ by The Japan Association of Industrial Health. ${ }^{14}$ As a biological exposure index (BEI), $5.0 \mathrm{mg} / 1$ of urinary 2,5 -hexanedione is proposed by $\mathrm{ACGIH}^{13}$ and $9.0 \mathrm{mg} / 1$ by Deutshe Forshungsgemeinshaft (DFG). ${ }^{15}$ In Japan we have a legal obligation since 1989 to measure 2,5-hexanedione in the urine of workers exposed to $n$-hexane. The exposed workers are classified into three groups by the concentration of urinary 2,5-hexanedione. The first group has a concentration below $2 \mathrm{mg} / 1$ of $2,5-$ hexanedione, the second group from 2 to $5 \mathrm{mg} / \mathrm{l}$, and the third group more than $5 \mathrm{mg} / \mathrm{l}$. The analytical method devised by Perbellini et al uses enzymatic and acid hydrolysis and double extraction with dichloromethane and evaporation of the solvent with nitrogen gas. ${ }^{16}$ Urinary metabolites of $\mathrm{n}$-hexane have been mostly measured by the method of Perbellini et $a l^{16}$ or slight modifications of this. It is time consuming, however, and some loss of 2,5-hexanedione occurs during concentration. The method of Fedtke and Bolt ${ }^{17}$ is simpler but it needs neutralisation to $\mathrm{pH}$ 7.0 after acid hydrolysis and is less sensitive than the method of Perbellini et $a l^{16}$ because the urine sampling volume is limited to only $1 \mathrm{ml}$. Recently, improved methods for the determination of 2,5hexanedione have been reported, ${ }^{1819}$ but few fundamental investigations have been made into the analytical conditions necessary for accurate and sensitive measurement of 2,5-hexanedione. The present study aimed to develop a simple and precise method for analysis of urinary 2,5-hexanedione. 


\section{Materials and methods CHEMICALS}

All reagents and chemicals were special or first grade, obtained from Tokyo Kasei Industry (Tokyo, Japan), Katayama Chemical (Osaka, Japan), and Wako Pure Chemical Industry (Osaka, Japan).

\section{INSTRUMENTATION}

Urine analyses were determined on a Shimadzu GC-R1A or GC-15A gas chromatograph equipped with flame ionisation detector. Columns were fused silica widebore (megabore) $0.53 \mathrm{~mm}$ internal diameter $\times 15 \mathrm{~m} \quad$ DB-1701 (14\% cyanopropyl phenyl polysiloxane), DB-1 (dimethyl polysiloxane), DB-5 (5\% diphenyl and 95\% dimethyl polysiloxane), DB-17 (50\% diphenyl and 50\% dimethyl polysiloxane), DB-210 (50\% trifluoropropyl and $50 \%$ methyl polysiloxane), and DB-WAX (polyethyleneglycol $20 \mathrm{M}$ ) all from J and W Scientific (CA, USA), and capillary columns $0.32 \mathrm{~mm}$ internal diameter $\times 30 \mathrm{~m} \mathrm{CBP}-1$ (equivalent to DB-1) and CBP-20 (equivalent to DB-WAX) from Shimadzu (Kyoto, Japan). Helium was used as the carrier gas at a flow rate of $15 \mathrm{ml} / \mathrm{min}$ for a widebore column and $2 \mathrm{ml} / \mathrm{min}$ for a capillary column. The temperatures of injector and detector were $120^{\circ} \mathrm{C}$ and $200^{\circ} \mathrm{C}$ respectively. The column temperature was programmed to be $50^{\circ} \mathrm{C}$ for the initial three minutes, then increased from $50^{\circ} \mathrm{C}$ to $100^{\circ} \mathrm{C}$ at $5^{\circ} \mathrm{C} / \mathrm{min}$; subsequently from $100^{\circ} \mathrm{C}$ to $200^{\circ} \mathrm{C}$ at $20^{\circ} \mathrm{C} / \mathrm{min}$ to purge the component extracted from urine. The gas chromatography-mass spectrometry analyses were performed with wide bore column DB-1701 and JEOL JMS-AX303 with an electron energy of $70 \mathrm{eV}$.

\section{URINE PROCESSING}

Urine samples were collected from 50 workers (27 women and 23 men) painting and spraying adhesives for car interiors in four factories. The samples were collected at the end of the workshift and kept at $0-4^{\circ} \mathrm{C}$ until analysis.

Urine was also collected from Wister strain male rats (body weight $260-300 \mathrm{~g}$ ) exposed to $2000 \mathrm{ppm}$ of $\mathrm{n}$-hexane continuously for $12 \mathrm{~h} /$ day.

\section{AIR SAMPLING}

The exposure concentration of $n$-hexane and other solvents were measured by a Pro Tek personal monitoring badge (Du Pont, USA). The badge was attached to the worker's collar during the workshift. After use, the badge was sealed tightly in a small bag and kept at $4^{\circ} \mathrm{C}$ until analysis. The carbon felt in the badge was steeped in $\mathrm{CS}_{2}$ for one hour and the solvent was injected into the gas chromatograph (column CBP-1 or CBP-20). Eight hour time weighted average concentrations (TWA) were calculated.

\section{URINE ANALYSIS}

A $5 \mathrm{ml}$ urine sample was placed in a glass tube $(10 \mathrm{ml}$ volume) with a screw cap. Concentrated hydrochloric acid (11.3 mole; $0.2 \mathrm{ml})$ was added. The mixture was heated for 30 minutes in a water bath (90-100 $\left.{ }^{\circ} \mathrm{C}\right)$, then cooled with water. Sodium chloride $(1.5 \mathrm{~g})$ and $1.0 \mathrm{ml}$ of dichloromethane containing $20 \mathrm{nl} / \mathrm{ml}$ each of 3-methyl-cyclohexanone and cyclohexanone as internal standards were added. The sample was shaken vigorously for three minutes and centrifuged at $3000 \mathrm{rpm}$ for five minutes. The dichloromethane layer was separated and dried with anhydrous $\mathrm{Na}_{2} \mathrm{SO}_{4}$ and $2 \mu \mathrm{l}$ of the solution was injected into the gas chromatograph. The concentration of 2,5-hexanedione was corrected to a specific gravity of 1.024 .

For a calibration curve $0,2 \cdot 5,5,10,15$, and $25 \mu \mathrm{g}$ of standard solution of 2,5-hexanedione were added to $5 \mathrm{ml}$ water and $1.5 \mathrm{~g}$ of sodium chloride was added. These solutions were extracted with dichloromethane and analysed as above (solutions are equivalent to $0,0 \cdot 5,1,2,3$, and $5 \mathrm{mg} / \mathrm{l}$ ).

\section{Results}

GAS CHROMATOGRAPHIC CONDITIONS

Extracts of urine from non-exposed persons were measured using various gas chromatographic columns. The table shows the results. The gas chromatograms of 2,5-hexanedione obtained from DB-1701, DB-1, and DB-5 columns showed less interference than those obtained from polar columns. Subsequently, therefore, urinary 2,5-hexanedione was determined mainly using the wide bore column

Comparison with various gas chromatography columns of concentration of 2,5-hexanedione in the urine of workers not exposed to n-hexane

\begin{tabular}{|c|c|c|c|c|c|c|c|c|}
\hline & \multicolumn{8}{|l|}{ Column type } \\
\hline & $D B-1701$ & $D B-1$ & $D B-5$ & $D B-17$ & $D B-210$ & $D B-W A X$ & $C B P-1$ & $C B P-20$ \\
\hline $\begin{array}{l}2,5 \text {-Hexanedione }(\mathrm{mg} / 1)^{\star} \\
\text { Range }(\mathrm{mg} / 1) \\
\text { Coefficient of variation }(\%)\end{array}$ & $\begin{array}{l}0.12 \pm 0.05 \\
0.05-0.2 \\
0.49\end{array}$ & $\begin{array}{l}0.15 \pm 0 \cdot 10 \\
0.05-0.4 \\
0.94\end{array}$ & $\begin{array}{l}0.11 \pm 0.05 \\
0.05-0.2 \\
0.44\end{array}$ & $\begin{array}{l}0.20 \pm 0.15 \\
0.05-0.5 \\
1.35\end{array}$ & $\begin{array}{l}0.53 \pm 0 \cdot 23 \\
0 \cdot 2-1 \cdot 1 \\
2 \cdot 12\end{array}$ & $\begin{array}{l}1 \cdot 84 \pm 0 \cdot 77 \\
0 \cdot 7-2 \cdot 9 \\
6 \cdot 99\end{array}$ & $\begin{array}{l}0 \cdot 18 \pm 0 \cdot 08 \\
0 \cdot 09-0 \cdot 35 \\
0 \cdot 73\end{array}$ & 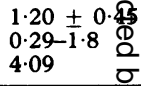 \\
\hline
\end{tabular}

The concentration of 2,5-hexanedione was calculated from the peak with the same retention time as standard 2,5-hexanedione.

*These values are mean (SD) of 10 urine samples. 


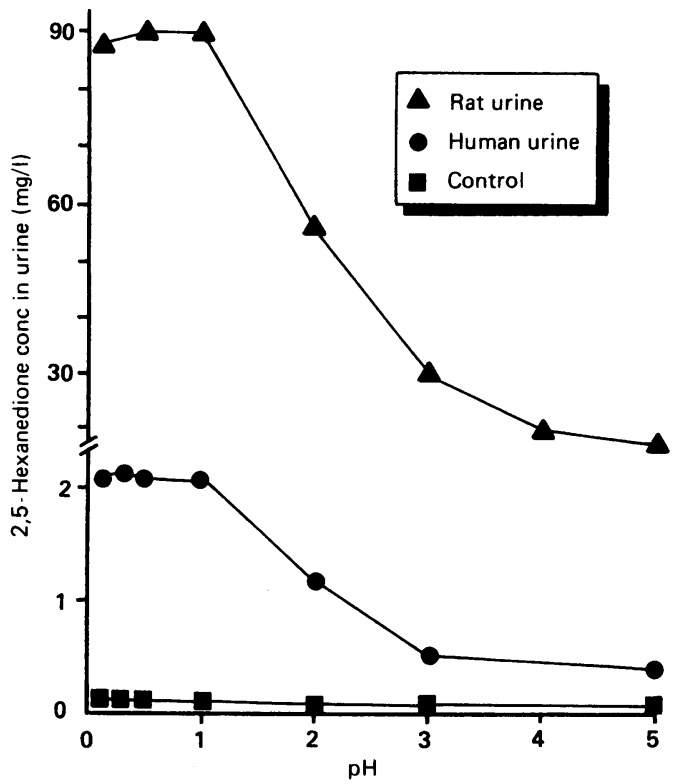

Figure 1 Effect of change in $\mathrm{pH}$ on 2,5-hexanedione concentration in urine from workers and rats exposed to n-hexane.

DB-1701. Cyclohexanone is used as an internal standard in gas chromatography, but in some cases an overlapping peak was observed. As well as cyclohexanone, we selected 3-methyl cyclohexanone as an internal standard. This has a retention time near to that of 2,5-hexanedione and few overlapping interfering compounds. For the determination of 2,5hexanedione the coefficient of variation by the internal standard method was three times more precise than that by the direct method. The detection limit of 2,5 -hexanedione in urine was $0.05-0.1 \mathrm{mg} / 1$ by extracting $5 \mathrm{ml}$ of urine in the present method.

\section{ACID HYDROLYSIS CONDITIONS}

We studied optimal $\mathrm{pH}$ conditions for acid hydrolysis with urine of workers exposed and not exposed to $n$-hexane, and rat urine. Figure 1 shows that the amount of 2,5-hexanedione depended on the adjusted $\mathrm{pH}$ in urine before heating the sample. 2,5-Hexanedione concentrations in urine of workers exposed to $\mathrm{n}$-hexane were consistently low from $\mathrm{pH}$ 5.0 to $\mathrm{pH} 3 \cdot 0$. 2,5-Hexanedione concentration rapidly increased, however, from $\mathrm{pH} 3.0$ to $\mathrm{pH} 1.0$ and reached a plateau at $\mathrm{pH} 1.0$. The curve for 2,5-hexanedione with changing $\mathrm{pH}$ in the urine of workers is similar to that for rat urine. 2,5Hexanedione in the urine of workers not exposed to $\mathrm{n}$-hexane was not increased even below $\mathrm{pH} 2 \cdot 0$.
Therefore, $\mathrm{pH}$ for acid hydrolysis was adjusted to around $\mathrm{pH} 0.5$ by adding $0.2 \mathrm{ml}$ concentrated hydrochloric acid. For 40 workers, the mean $\mathrm{pH}$ of the urine, to which $0.2 \mathrm{ml}$ of concentrated hydrochloric acid was added was 0.49 (SD 0.07), range 0.3-0.7.

\section{EFFECT OF PH ON THE STABILITY OF URINARY METABOLITES}

The effect of $\mathrm{pH}$ on the stability of 2,5-hexanedione, 2,5-dimethylfuran, and 2-hexanol, (urinary metabolites of $n$-hexane) was studied. Even below $\mathrm{pH} 2.0$ the amount of 2,5-hexanedione and 2-hexanol were not changed. Figure 2 shows, however, that 2,5-dimethylfuran concentration was rapidly decreased below $\mathrm{pH} 3.0$ and disappeared below $\mathrm{pH}$ $2 \cdot 0$. On the other hand, the peak of 2,5-hexanedione appeared below $\mathrm{pH} 3 \cdot 0$. Therefore, after acid treatment to give a pH of less than 1.0 the urinary metabolite 2,5-dimethylfuran was considered to be totally converted to 2,5-hexanedione and determined as 2,5-hexanedione in the present method.

\section{EFFECT OF TIME AND TEMPERATURE ON ACID} HYDROLYSIS

We studied the effect of temperature $\left(60-100^{\circ} \mathrm{C}\right)$ and heating time (0-60 minutes) on acid hydrolysis. The amount of 2,5-hexanedione in the urine increased with increases in temperature and heating time and reached a maximum at over $80^{\circ} \mathrm{C}$ and 15 minutes. The conditions for acid hydrolysis, therefore, were chosen to be $90-100^{\circ} \mathrm{C}$ and 30 minutes.

\section{EXTRACTION OF 2,5-HEXANEDIONE FROM HYDROLYSED} URINE

We investigated an effective and simple extraction method. The extraction efficiencies of five solvents (dichloromethane, ethyl acetate, diethyl ether, isopropyl ether, and n-pentane) were compared. All

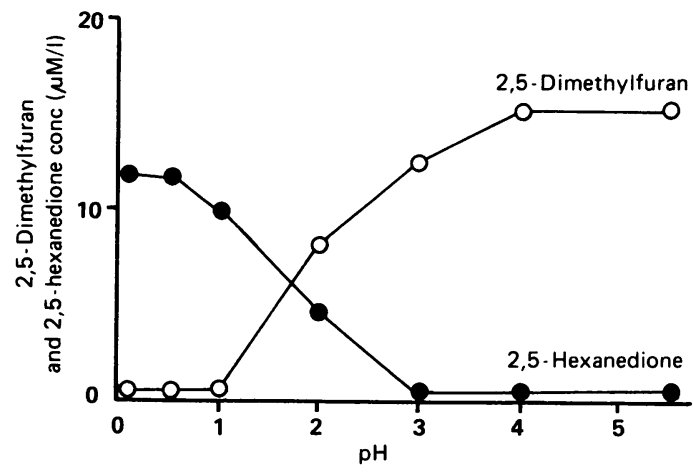

Figure 2 Effect of $p H$ on the conversion of 2,5-dimethylfuran to 2,5-hexanedione. 


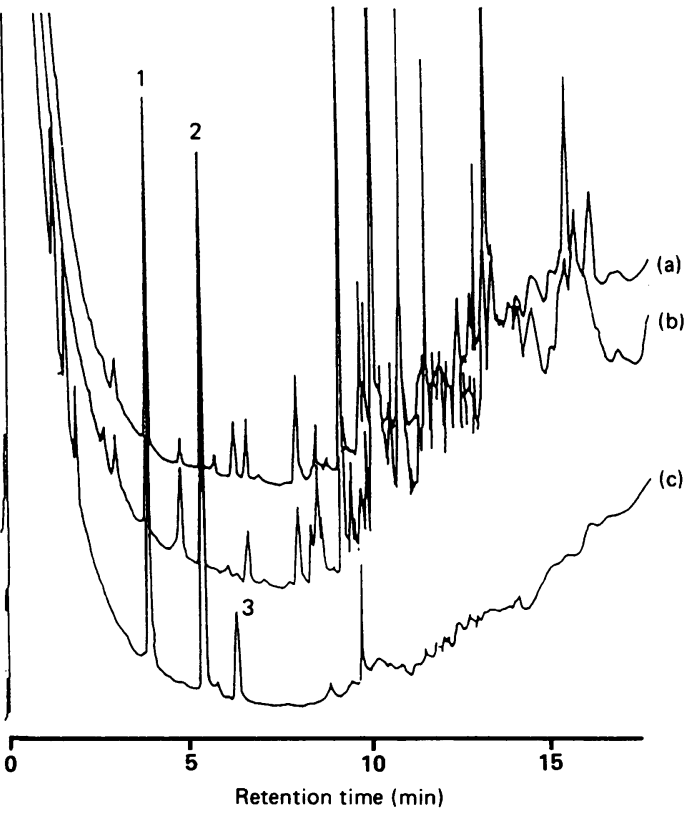

Figure 3 Gas chromatograms of the urine of workers exposed and not exposed to n-hexane, using the proposed method: (a) the urine of worker exposed to n-hexane;

(b) the urine of worker not exposed to n-hexane;

(c) standard solution (peak 1, cyclohexanone, peak 2,

3-methyl cyclohexanone, peak 3, 2,5-hexanedione).

the solvents had good extraction efficiencies for 2-hexanol and 2,5-dimethylfuran. Dichloromethane, however, had greater efficiency for 2,5-hexanedione than the other solvents and we chose this as the extracting solvent. Using $1 \mathrm{ml}$ of dichloromethane to extract from $5 \mathrm{ml}$ of aqueous solutions the extraction efficiency was about $95 \%$ for 3-methyl cyclohexanone and cyclohexanone used as internal standard but about $70 \%$ for 2,5 -hexanedione. Therefore, the effect of sodium chloride on extraction efficiency of 2,5-hexanedione was studied. The extraction efficiency was improved to about $90 \%$ by adding $1.5 \mathrm{~g}$ of sodium chloride.

\section{RECOVERY OF 2,5-HEXANEDIONE ADDED TO HUMAN}

\section{URINE}

Recovery of $5 \mathrm{mg}$ 2,5-hexanedione added to urine was determined five times. Mean recovery was $\mathbf{8 6 \cdot 2}$ (SD 1.3$) \%$. The recovery of 2,5-hexanedione was improved to 97.6 (SD 1.7; CV 1.8)\%, however, by comparison with a calibration curve made by extraction of an aqueous solution of 2,5-hexanedione in the same way as the urine sample.

IDENTIFICATION OF URINARY 2,5-HEXANEDIONE Figure 3 shows a gas chromatogram of the extracted urine of non-exposed workers and workers exposed to n-hexane, with the proposed method. The peak of 2,5-hexanedione in urine samples from workers exposed to $\mathrm{n}$-hexane was seen at the same retention time as standard 2,5-hexanedione. The mass spectrum of this urinary peak was identical with that of standard 2,5-hexanedione (fig 4).

STABILITY OF 2,5-HEXANEDIONE DURING STORAGE

We studied the stability of 2,5-hexanedione using urine from rats exposed to $\mathrm{n}$-hexane, diluted with human urine. The urine mixture was allowed to stand at $25^{\circ} \mathrm{C}, 4^{\circ} \mathrm{C}$, or $-20^{\circ} \mathrm{C}$ for 30 days. Urinary 2,5-hexanedione concentration at $-20^{\circ} \mathrm{C}$ and $4^{\circ} \mathrm{C}$ was unchanged by 30 days. At $25^{\circ} \mathrm{C}$, however, urinary 2,5-hexanedione concentration was less after one day and was one fifth of the initial concentration after 15 days.

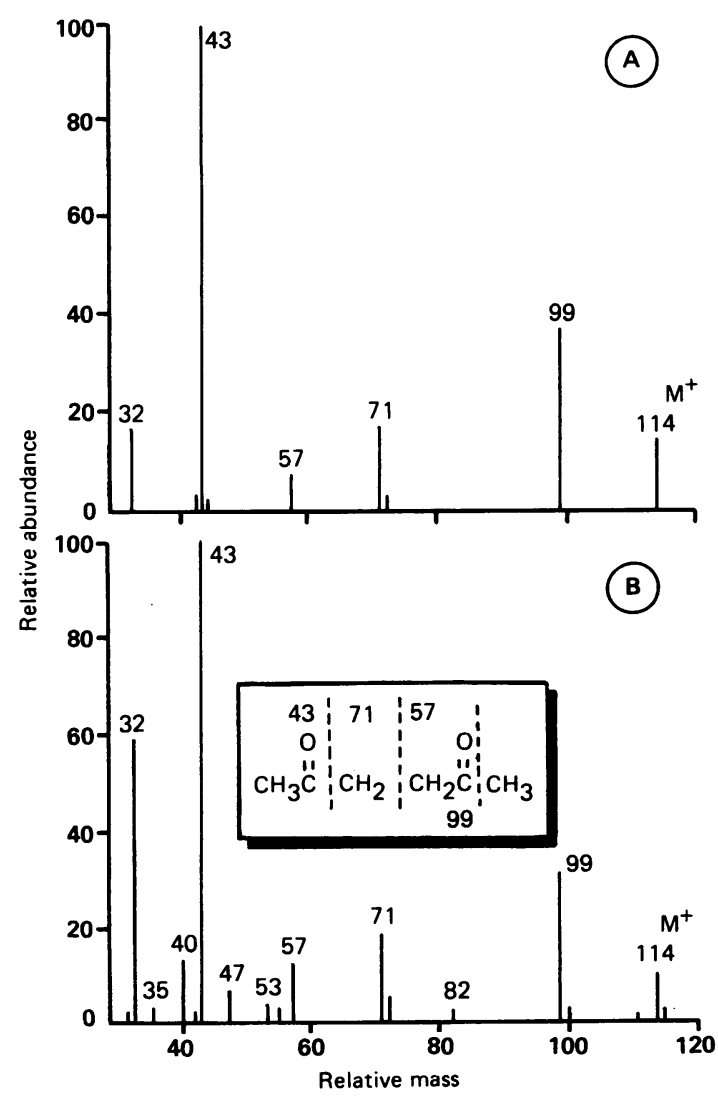

Figure 4 Mass spectrum of 2,5-hexanedione: $(A)$ standard solution; $(B)$ urine of worker exposed to n-hexane. 


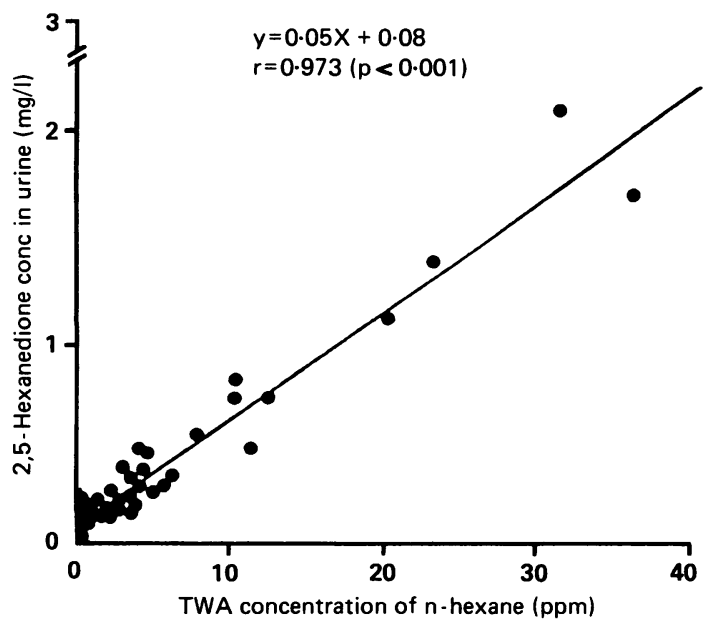

Figure 5 Relation between exposure concentration and 2,5-hexanedione concentration in urine of workers.

RELATION BETWEEN THE EXPOSURE CONCENTRATION OF N-HEXANE AND URINARY 2,5-HEXANEDIONE

Mean TWA concentrations of solvents at the four factories were: factory $1(n=20), n$-hexane $2 \cdot 6$ (SD 3.6) ppm, toluene 24.6 (SD 41.8) ppm, and MEK $29 \cdot 2$ (SD 26.6) ppm; factory $2(\mathrm{n}=4)$, n-hexane $28 \cdot 2$ (SD 6.8) ppm and toluene $22 \cdot 2$ (SD 4.8) ppm; factory $3(\mathrm{n}=4)$, n-hexane $0 \cdot 1(\mathrm{SD} 0 \cdot 1) \mathrm{ppm}$ and toluene 2.5 (SD 1.2) ppm; factory $4(\mathrm{n}=22)$, n-hexane 3.6 (SD 2.7) ppm and toluene 6.7 (SD 4.0) ppm. 2,5Hexanedione concentrations in the urine of 50 workers were determined by the present method. Figure 5 shows the good correlation between exposure concentration of $\mathrm{n}$-hexane and urinary 2,5-hexanedione.

\section{Discussion}

The environmental concentration of organic solvent is useful for estimating exposure, but it does not always accurately reflect the intake of the individual worker. Therefore, biological monitoring using urinary metabolites is an important method for the actual assessment of exposure to organic solvents. Many investigations show that urinary 2,5 -hexanedione is suitable as an indicator of exposure to $n$-hexane..$^{7-11}$ Perbellini et $a l^{162021}$ have investigated the urinary metabolites of n-hexane. In 1980 they reported that 2,5-dimethylfuran, 2-hexanol, 2,5-hexanedione, and $\gamma$-valerolactone were detected in the urine of workers exposed to $n$-hexane in shoe factories. The method used enzymatic and acid hydrolysis $(\mathrm{pH} 2 \cdot 0)$, double extraction with dichloromethane, and concentration by evaporation with a stream of nitrogen gas. This method is, however, time consuming for the quantitative analysis of urinary $\mathrm{n}$-hexane metabolites. Fedtke and Bolt developed a simple method using acid hydrolysis ( $\mathrm{pH} 0 \cdot 1$ ) and cartridges for extraction of $\mathrm{n}$-hexane metabolites in $1 \mathrm{ml}$ urine. ${ }^{22}$ Their investigations of urinary $n$-hexane metabolites showed that the conjugated precursor that converted to $2,5-$ hexanedione after acid hydrolysis was 4,5dihydroxy-2-hexanone and that the enzymatic hydrolysis step was not necessary. ${ }^{12172223}$ During urine analysis, this metabolite is converted to $2,5-$ dimethylfuran by weak acid hydrolysis and to $2,5-$ hexanedione by strong acid hydrolysis. Urinary 2,5hexanedione is a useful indicator for biological monitoring, however, because it correlates well with exposure to $\mathrm{n}$-hexane. In our present study 2,5-dimethylfuran was found to convert to 2,5hexanedione below $\mathrm{pH} 1 \cdot 0$. Therefore, 4,5dihydroxy-2-hexanone and 2,5-dimethylfuran as metabolites of $n$-hexane in the urine of workers exposed to $n$-hexane could be measured as 2,5hexanedione by hydrolysing below pH 1.0.

Sampling volumes of urine for analysis were $10 \mathrm{ml}$ (Perbellini et al $^{16}$ ) and $1 \mathrm{ml}$ (Fedtke and Bolt ${ }^{22}$ ). The detection limit of 2,5-hexanedione was generally $0.5-$ $1.0 \mathrm{ng}$ by gas chromatography. Therefore, we selected $5 \mathrm{ml}$ as a sampling volume of urine, by which the detection limit for measurement of 2,5-hexanedione concentration in urine was $0.05-0.1 \mathrm{mg} / \mathrm{l}$. For the determination of 2,5-hexanedione, Perbellini et al $^{16}$ incubated the urine sample at $\mathrm{pH} 4.8$ with $\beta$ glucuronidase for 24 hours and then heated it in boiling water at $\mathrm{pH} 2.0$ for 30 minutes. Fedtke and Bolt hydrolysed the urine sample in boiling water at $\mathrm{pH} 0.1$ for 30 minutes. We selected $\mathrm{pH} 0.5$ because acid hydrolysis at $\mathrm{pH} 2.0$ does not cause maximum release of 2,5-hexanedione and 2,5-hexanedione does not break down between $\mathrm{pH} 0 \cdot 1$ and $\mathrm{pH} 0.5$. Furthermore, the interfering peaks in gas chromatograms were less at $\mathrm{pH} 0.5$ than at $\mathrm{pH} 0 \cdot 1$.

We also studied the effect of temperature and time on the acid hydrolysis. The amount of 2,5-hexanedione after acid hydrolysis reached a maximum at over $80^{\circ} \mathrm{C}$ and by 15 minutes. Therefore, we chose the condition at $90-100^{\circ} \mathrm{C}$ and 30 minutes for acid hydrolysis.

For the extraction of 2,5-hexanedione from hydrolysed urine, dichloromethane has been traditionally used as an extracting solvent. Recently, the fact that dichloromethane has a weak carcinogenicity was reported. ${ }^{24}$ Therefore, we studied other extracting solvents that had good extractability and were safer than dichloromethane. Dichloromethane was found to be the best extracting solvent, however, for urinary $\mathrm{n}$-hexane metabolites so we used small amounts of dichloromethane as the extracting solvent and did not concentrate the extract.

About $70 \%$ of 2,5-hexanedione in $5 \mathrm{ml}$ of aqueous solution was extracted with $1 \mathrm{ml}$ of dichloromethane. The addition of sodium chloride improves, the recovery of 2,5-hexanedione from the solution after 
acid hydrolysis by some $20 \%$. When 2,5 -hexanedione solution was added to two urine samples (specific gravity 1.031 and 1.008 ) after acid hydrolysis, the recoveries of 2,5-hexanedione extracted with dichloromethane were $77 \%$ and $72 \%$ respectively. The difference in the recovery was not apparent after adding sodium chloride to the urine. Therefore, the addition of sodium chloride might also reduce the variation in recovery due to differences in specific gravity of urine.

We have checked various types of gas chromatography columns to separate the peak of 2,5hexanedione from interfering peaks. The interfering peaks did not appear when using non-polar or weak polar columns and we selected columns DB-1701 and DB-1 for the analysis.

Fedtke and Bolt ${ }^{22}$ showed that the amount of 2,5hexanedione detected in urine of workers not exposed to $\mathrm{n}$-hexane was 0.45 (SD 0.20$) \mathrm{mg} / \mathrm{l}$ ( $\mathrm{n}=12$, range $0.12-0.78 \mathrm{mg} / \mathrm{l}$ ). Our results were $0.12(\mathrm{SD} 0.05) \mathrm{mg} / \mathrm{l}(\mathrm{n}=10$, range $<0.1-0.2 \mathrm{mg} / \mathrm{l})$, which were close to the detection limits on analysing by DB-1701 column. The difference between these results might be due to the difference of $\mathrm{pH}$ on acid hydrolysis. The reason is not clearly understood, but at least the concentrations of urinary 2,5-hexanedione in non-exposed persons measured by the proposed method were near the detection limit.

The correlation between level of $n$-hexane exposure and 2,5-hexanedione concentration in the urine of 50 workers at the end of the workshift is good at low concentrations of $n$-hexane. The concentration of urinary 2,5-hexanedione corresponding to an $\mathrm{n}$-hexane exposure concentration of $50 \mathrm{ppm}$ was $2.7 \mathrm{mg} / \mathrm{l}$ in the present study. Other authors reported $5.4 \mathrm{mg} / 1,{ }^{7} \quad 2.7 \mathrm{mg} / 1,{ }^{8} \quad 3.2 \mathrm{mg} / 1,{ }^{9} \quad 4.2 \mathrm{mg} / 1,{ }^{10}$ and $1.6 \mathrm{mg} / 1 .{ }^{11}$ We think that these differences may be due to the difference in method of analysis. In these reports 2,5-hexanedione was determined by the method of Perbellini et $a l^{16}$ or modifications of this. Gas chromatographic columns used for determining 2,5-hexanedione were usually polar (polyethylene glycol $20 \mathrm{M}$ (Carbowax $20 \mathrm{M}$, PEG20 M, DBWAX, CBP-2 etc)), although Iwata et al ${ }^{8526}$ used a non-polar column OV-101. The mixed exposure with other solvents such as toluene and MEK might have some effects on the excretion of urinary 2,5hexanedione. ${ }^{852627}$ Mean TWA concentrations of toluene and MEK in factory 1 were 24.6 and $29.1 \mathrm{ppm}$, respectively but the concentration of $n$ hexane $(2.6 \mathrm{ppm})$ was too low to allow the assessment of the effect of other solvents on the excretion of urinary 2,5-hexanedione. Mean TWA concentrations of $\mathrm{n}$-hexane and toluene in factory 2 were $28 \cdot 1$ and $22 \cdot 2 \mathrm{ppm}$, respectively, however, and a definite effect of other solvents on concentration of 2,5hexanedione was not suggested in the present study. These problems will be resolved by ongoing investi- gations with mixed solvents using the same analytical method.

In summary, in this study, we have developed a simpler and more precise analytical method of urinary 2,5-hexanedione than previous methods. Some similarities exist with two other recent reports of improved methods. ${ }^{18}{ }^{19}$ Our present method showed a high correlation between urinary 2,5-hexanedione and exposure to $n$-hexane. The method will be useful for biological monitoring of exposure to $n$-hexane.

1 Wada $Y$, Okamoto S, Takagi S. Intoxication polyneuropathy following exposure to n-hexane. Clin Neurol Neurosurg 1965;5:591-7.

2 Yamada $S$. Intoxication polyneuropathies in the workers exposed to $\mathrm{n}$-hexane. Japanese Journal of Industrial Health 1967;9:651-9.

3 Herskowitz A, Ishii N, Schaumburg HH. n-Hexane neuropathy. A syndrome occurring as a result of industrial exposure. $N$ Engl J Med 1971;285:82-5.

4 Krasavage WJ, O'Donoghue JL, DiVincenzo GD, Terhaar C. The relative neurotoxicity of methyl-n-butyl ketone, nhexane and their metabolites. Toxicol Appl Pharmacol 1980;52:433-41.

5 Couri D, Milks $M$. Toxicity and metabolism of the neurotoxic hexacarbons $\mathrm{n}$-hexane, 2-hexanone, and 2,5-hexanedione. Annual Review of Pharmacology and Toxicology 1982;22 145-66.

6 Governa M, Caliste R, Coppa G, Tagliavento G, Colombe A, Troni $W$. Urinary excretion of 2,5 -hexanedione and peripheral polyneuropathies in workers exposed to hexane. $J$ Toxicol Environ Health 1987;20:219-28.

7 Perbellini L, Brugnone F, Faggionato G. Urinary excretion of the metabolites of n-hexane and its isomers during occupational exposure. Br J Ind Med 1981;38:20-6.

8 Iwata M, Takeuchi Y, Hisanaga N, Ono Y. A study on biological monitoring of n-hexane exposure. Int Arch Öccup Environ Health 1983;51:253-60.

9 Mutti A, Falzoi M, Lucertini S, et al. n-Hexane metabolism in occupationally exposed workers. Br J Ind Med 1984;41:533-8.

10 De Rosa E, Bartolucci GB, Perbellini L, Brugnone F, Rausa G. Environmental and biological monitoring of exposure to toluene, styrene, and n-hexane. Applied Industrial Hygiene 1988;3:332-7.

11 Ahonen I, Schimberg RW. 2,5-Hexanedione excretion after occupational exposure to n-hexane. $\mathrm{Br} J$ Ind $M \mathrm{H}^{\prime} d 1988$ 45:133-6.

12 Fedtke N, Bolt HM. 4,5-Dihydroxy-2-hexanone. A new metabolite of $n$-hexane and of 2,5-hexanedione in rat urine. Biomed Environ Mass Spectrom 1987;14:563-72.

13 American Conference of Governmental Industrial Hygienists Threshold limit values and biological exposure indices for 1989 1990. Cincinnati, Ohio: ACGIH, 1990.

14 The Japan Association of Industrial Health: Recommendations of TLVs. Japanese Journal of Industrial Health 1989;31:262.

15 Deutsche Forschungsgemeinshaft. Maximum concentrations at the workplace and biological tolerance values for working materials 1989. New York: VCH Publishers, 1989.

16 Perbellini L, Brugnone F, Silvestri R, Gaffuri E. Measurement of the urinary metabolites of $\mathrm{n}$-hexane, cyclohexane and their isomers by gas chromatography. Int Arch Occup Environ Health 1981;48:99-106.

17 Fedtke N, Bolt HM. Methodological investigations on the determination of $\mathrm{n}$-hexane metabolites in urine. Int Arch Occup Environ Health 1986;57:149-58.

18 Perbellini L, Amoros DM, Llorens AC, Giuliani C, Brugnone F An improved method of analysing 2,5-hexanedione in urine $\mathrm{Br} J$ Ind Med 1990;47:421-4.

19 Kawai T, Mizunuma K, Yasugi T, Uchida Y, Ikeda M. The method of choice for the determination of 2,5 -hexanedione as an indicator of occupational exposure to n-hexane. Int Arch Occup Environ Health 1990;62:403-8.

20 Perbellini L, Brugnone F, Pavan I. Identification of the metabolites of $\mathrm{n}$-hexane, cyclohexane, and their isomers in men's urine. Toxicol Appl Pharmacol 1980;53:220-9.

21 Perbellini L, Amantini MC, Brugnone F, Frontali N. Urinary 
excretion of n-hexane metabolites. Arch Toxicol 1982;50: 203-15.

22 Fedtke N, Bolt HM. Detection of 2,5-hexanedione in the urine of persons not exposed to n-hexane. Int Arch Occup Environ Health 1986;57:143-8.

23 Fedtke N, Bolt HM. The relevance of 4,5-dihydroxy-2hexanone in the excretion kinetics of n-hexane metabolites in rat and man. Arch Toxicol 1987;61:131-7.

24 International Agency for Research on Cancer. Monograph on the evaluation of the carcinogenic risk of chemicals to humans. Vol 41. Lyon: IARC, 1986:43-85.

25 Iwata M, Takeuchi $Y$, Hisanaga N, Ono $Y$. Changes of $n$-hexane metabolites in urine of rats exposed to various concentrations of $\mathrm{n}$-hexane and to its mixture with toluene or MEK. Int Arch Occup Environ Health 1983;53:1-8.

26 Iwata M, Takeuchi $Y$, Hisanaga N, Ono Y. Changes of $n$-hexane neurotoxicity and its urinary metabolites by long-term coexposure with MEK or toluene. Int Arch Occup Environ Health 1984;54:273-81.

27 Shibata E, Huang J, Ono $\mathrm{Y}$, et al. Changes in urinary $\mathrm{n}$-hexane metabolites by co-exposure to various concentrations of methyl ethyl ketone and fixed n-hexane levels. Arch Toxicol 1990;64:165-8.

Accepted 17 December 1990 